\title{
Enantioselective synthesis of a cyclopentannulated kalafungin analogue
}

\author{
Margaret A. Brimble*a and John F. McEwan ${ }^{b}$ \\ ${ }^{a}$ Department of Chemistry, University of Auckland, 23 Symonds St., Auckland, New Zealand. \\ Tel: +6493737599 ext 8259; Fax: +6493737422 \\ ${ }^{b}$ School of Chemistry, University of Sydney, Eastern Ave., Camperdown, NSW 2006, Australia \\ E-mail: m.brimble@auckland.ac.nz
}

(received 13 Sep 00; accepted 26 Nov 00; published on the web 04 Dec 00)

DOI: http://dx.doi.org/10.3998/ark.5550190.0001.608

\begin{abstract}
The enantioselective synthesis of a cyclopentannulated analogue $\mathbf{8}$ of the pyranonaphthoquinone antibiotic kalafungin $\mathbf{1}$ is described. Addition of cyclopentadiene to naphthoquinone $\mathbf{2}$ which bears a pantalactone chiral auxiliary at C-2, afforded cyclopentannulated naphthofuran $\mathbf{4}$ after tin(IV) chloride induced fragmentation of the initial Diels-Alder adduct $\mathbf{3}$. The pantolactone auxiliary was then removed using lithium borohydride and the resultant aldehyde $\mathbf{5}$ converted to a methyl ketone $\mathbf{6}$ by treatment with methyl lithium followed by oxidation with manganese dioxide. The enantiomeric excess of methyl ketone $\mathbf{6}$ obtained in this manner was established to be $96 \%$ by chiral HPLC. Oxidative rearrangement of methyl ketone 6 using silver (II) oxide and nitric acid afforded lactol $\mathbf{7}$ which was reduced to cyclopentannulated pyranonaphthoquinone $\mathbf{8}$ using triethylsilane and trifluoroacetic acid.
\end{abstract}

Keywords: Pyranonaphthoquinones, asymmetric Diels-Alder, pantolactone, fragmentation

\section{Introduction}

The pyranonaphthoquinone family of antibiotics, exemplified by kalafungin $\mathbf{1}$ have attracted considerable synthetic interest 1 due to their proposed ability to act as bioreductive alkylating agents via quinone methide intermediates. Despite the important biological activity displayed by this family of antibiotics very few methods for the enantioselective synthesis of pyranonaphthoquinones have been reported.2 Our approach to the synthesis of several members 
of the pyranona-phthoquinone antibiotics has focused on the addition of a silyloxyfuran to a naphthoquinone followed by oxidative rearrangement of the resultant furonaphthofuran adduct (Scheme 1).3 Attempts to extend this strategy to an enantioselective synthesis of kalafungin 1 and related natural products have focused on the use of bis(oxazoline)-metal complexes as chiral catalysts in the addition of the appropriate dienes to activated naphthoquinones 4 and the use of naphthoquinones bearing a chiral auxiliary at $\mathrm{C}-2$ as a chiral dienophile. The latter approach met with better success than the former in that good levels of diastereomeric excess were observed in reactions of naphthoquinones bearing pantolactone as a chiral auxiliary at $\mathrm{C}-2$, with the dienes cyclopentadiene5 and 2-trimethylsilyloxyfuran.6<smiles>COc1ccco1</smiles><smiles></smiles><smiles>COc1cccc2c1C(=O)C1=C(C2=O)[C@]2(C)OC(=O)C[C@H]2O[C@]1(C)O</smiles>

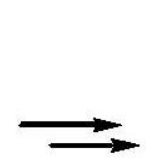<smiles>C[C@H]1O[C@H]2CC(=O)O[C@H]2C2=C1C(=O)c1c(O)cccc1C2=O</smiles>

\section{Scheme 1}
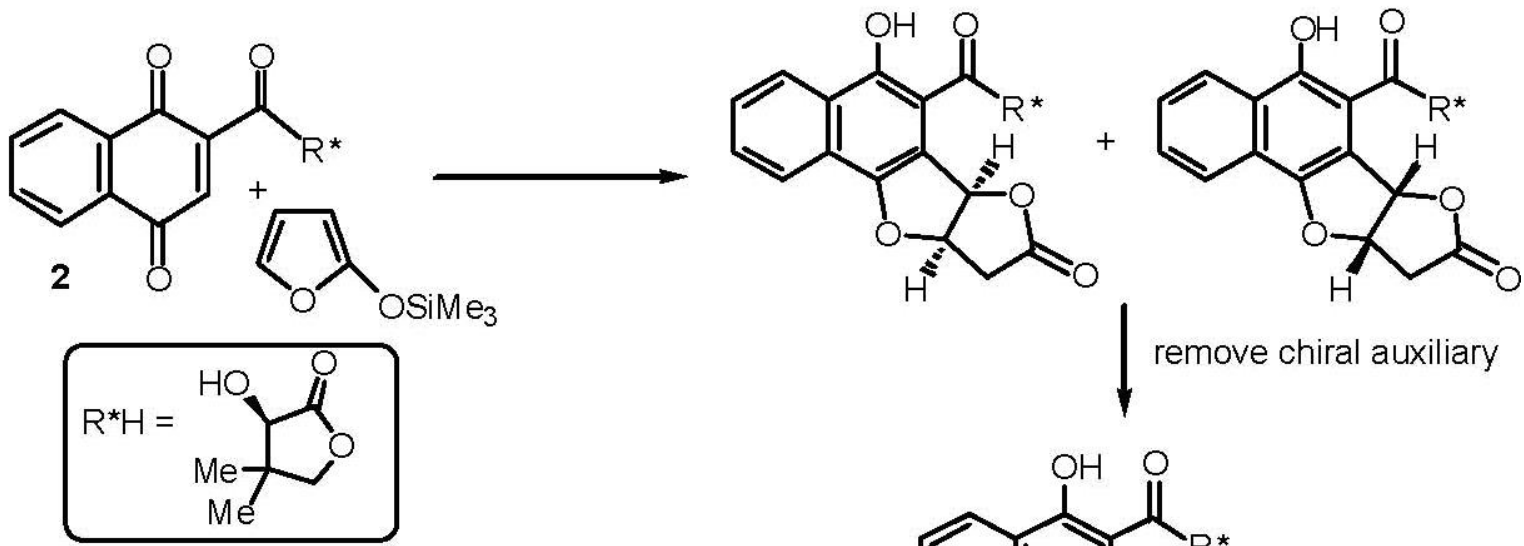<smiles>[R2]C(=O)c1c(O)c2ccccc2c2oc(CC(=O)O)cc12</smiles> 


\section{Scheme 2}

Removal of the pantolactone chiral auxiliary from the sensitive furofuran adducts (Scheme 2) met with little success in that aromatisation of the $\gamma$-lactone readily occurred. We therefore focused our attention on the less sensitive cyclopentadiene adducts and herein report an enantioselective synthesis of the cyclopentannulated analogue 8 of kalafungin 1 (Scheme 3).

\section{Results and Discussion}

The chirality present in the cyclopentannulated analogue 8 of kalafungin 1 was generated via Lewis acid induced fragmentation of the Diels-Alder adduct 3 (formed by the addition of cyclopentadiene to chiral naphthoquinone 2) to the cyclopentannulated dihydronaphthofuran 4 . Aldehyde 5 was then obtained after reductive removal of the pantolactone chiral auxiliary and transformed to methyl ketone 6 by addition of methyl lithium and subsequent oxidation using manganese dioxide. Oxidative rearrangement of the cyclopenta[b]naphtho[1,2-d]furan 6 to a cyclopenta[b]naphtho[2,3-d]pyran-6,11-dione 7 was then achieved using silver(II) oxide and nitric acid. Finally reduction of the lactol 7 to a cyclic ether 8 was achieved using triethylsilane and trifluoroacetic acid.

In an earlier study ${ }^{5}$ of the diastereoselectivity of the Diels-Alder addition of cyclopentadiene to 1,4-naphthoquinones bearing a chiral auxiliary at C-2, it was established that the pantolactone auxiliary afforded the best diastereoselectivity when using zinc(II) chloride as the Lewis acid. Furthermore the stereochemistry of this cycloaddition was established by X-ray crystallography to be that wherein the cyclopentadiene added to the less hindered top face of the naphthoquinone 2 due to the shielding of the lower face by the pantolactone auxiliary. Adduct 3 was obtained in 96\% diasteromeric excess and was smoothly converted to 4 using one equivalent of tin(IV) chloride in dichloromethane in $65 \%$ yield. The pantolactone chiral auxiliary was then removed smoothly upon treatment of 4 with lithium borohydride.

In order to prepare analogues of kalafungin 1, aldehyde 5 required conversion to methyl ketone 6. Methyl ketone $\mathbf{6}$ was therefore prepared in $72 \%$ yield by treatment of aldehyde 5 with excess methyl lithium followed by immediate oxidation of the resultant secondary alcohol with activated manganese dioxide in dichloromethane. The optical purity of methyl ketone $\mathbf{6}$ was determined to be $96 \%$ e.e. by high pressure liquid chromatography on a Pirkle Type 1-A column using hexane / $0.5 \%$ isopropyl alcohol as solvent. Hence it was established that the diastereomeric excess (96\% d.e.) of the initial Diels-Alder reaction adduct 3 was completely reflected in the enantiomeric excess observed for methyl ketone $\mathbf{6}$. 


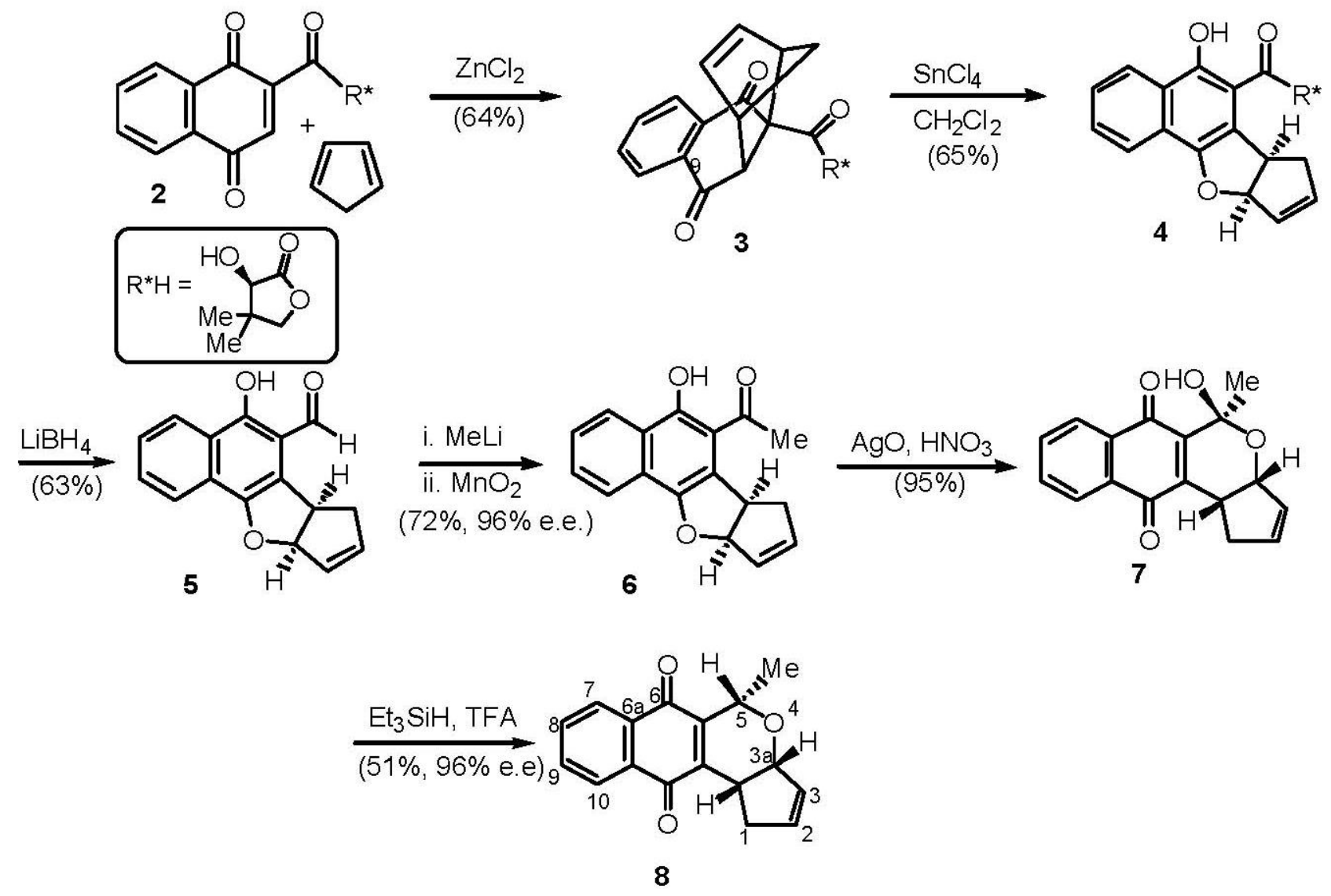

\section{Scheme 3}

Methyl ketone 6 was then oxidised using silver(II) oxide and nitric acid to afford pyranonaphthoquinone 7 in $95 \%$ yield. In the $1 \mathrm{H}$ NMR spectrum of 7 a three proton singlet at $\delta$ $1.82 \mathrm{ppm}$ was assigned to the methyl group and a multiplet at $\delta 4.90-5.04 \mathrm{ppm}$ was assigned to 3a-H. The 13C NMR spectrum exhibited characteristic peaks at $\delta 28.2 \mathrm{ppm}, \delta 36.0 \mathrm{ppm}, \delta 73.9$ ppm and $\delta 86.7$ ppm assigned to the methyl, C-11b, C-3a and C-5 carbons.

The unstable lactol 7 was subsequently reduced with triethylsilane and trifluoroacetic acid to form kalafungin analogue 8 in $50 \%$ yield. A three proton doublet $(J 6.6 \mathrm{~Hz})$ at $\delta 1.57 \mathrm{ppm}$ in the $1 \mathrm{H}$ NMR spectrum was assigned to the methyl group and a multiplet at $\delta 4.45-4.59 \mathrm{ppm}$ was assigned to $5-\mathrm{H}$. A one proton multiplet at $\delta 4.70-4.85 \mathrm{ppm}$ was assigned to $3 \mathrm{a}-\mathrm{H}$. Nuclear Overhauser enhancements (nOe) between $5-\mathrm{H}$ and $3 \mathrm{a}-\mathrm{H}(0.9 \%)$ and between $3 \mathrm{a}-\mathrm{H}$ and $11 \mathrm{~b}-\mathrm{H}$ $(3.2 \%)$ confirmed that $5-\mathrm{H}$ was cis with respect to the bridgehead protons $3 \mathrm{a}-\mathrm{H}$ and $11 \mathrm{~b}-\mathrm{H}$. This is consistent with axial delivery of hydride from triethylsilane as reported by Kraus et al.7 The enantiomeric excess of $\mathbf{8}$ was established as $96 \%$ e.e.by 1H NMR spectroscopy using the chiral shift reagent (+)-Eu(hfc) $)_{3}$. 
In summary the successful synthesis of kalafungin analogue $\mathbf{8}$ has provided a viable enantioselective route to cyclopentannulated analogues of pyranonaphthoquinone antibiotics such as kalafungin $\mathbf{1}$ and demonstrates the synthetic utility of Diels-Alder adducts of cyclopentadiene with 1,4-naphthoquinones bearing a chiral auxiliary at C-2.

\section{Experimental Section}

General Procedures. Tetrahydrofuran was distilled from sodium-benzophenone ketyl immediately before use. Petroleum ether refers to the fraction with bp $40-60{ }^{\circ} \mathrm{C}$ and was redistilled before use. Dichloromethane was distilled from calcium hydride immediately before use. Flash column chromatography was performed on Merck silica gel 60 (230-400 mesh) using the eluent specified under medium pressure. All reagents were purchased from commercial suppliers and were used without further purification. Melting points are uncorrected. Optical rotations were measured using a PolAAR 2001 Polarimeter in various solvents at the temperature and concentration (g.100 mL-1) indicated. Specific rotations are given in 10-1 deg.cm2.g-1. Readings were taken using the $589.3 \mathrm{~nm}$ sodium line in a $0.5 \mathrm{dm}$ cell. Infrared spectra were recorded using a Perkin Elmer 1600 Series FTIR spectrometer as a thin film on a single sodium chloride plate seated in the apparatus on a custom made perch. 1H NMR spectra were recorded on a Bruker AC200B spectrometer (200.13 MHz) or a Bruker AM400 (400.12 MHz) spectrometer. 13C NMR spectra were recorded on a Bruker AC200 (50.3 MHz) spectrometer at ambient temperatures with complete decoupling and were interpreted with the aid of DEPT 135 and DEPT 90 experiments. High Performance Liquid Chromatography (HPLC) was performed using Waters and Associates HPLC instrumentation fitted with a Pirkle Type 1A column (21.5 $\mathrm{mm}$ i.d. $\mathrm{x} 25 \mathrm{~mm}$ ) with a flow rate of $1.5 \mathrm{~cm} 3 / \mathrm{min}$ and $0.5 \%$ ethyl acetate in hexane as eluent.

\section{$(6 \mathrm{~b} R, 9 \mathrm{a} R)$-6-Formyl-6b,9a-dihydro-5-hydroxy-7H-cyclopenta[b]naphtho[1,2-d]-furan}

To a solution of cyclopenta[b]naphtho[1,2-d]furan 4 (380 $\mathrm{mg}, 1.0 \mathrm{mmol})$ which was prepared from naphthoquinone 2 and cyclopentadiene according to the published procedure, 5 in THF $\left(2 \mathrm{~cm}^{3}\right)$, was added dropwise a solution of lithium borohydride $(12.0 \mathrm{mg}, 2.0 \mathrm{mmol})$ in THF (2.0 $\mathrm{cm}^{3}$ ). After stirring for $30 \mathrm{~min}$ the solvent was removed under reduced pressure and the residue redissolved in dichloromethane $\left(15 \mathrm{~cm}^{3}\right)$. The solution was washed with $10 \%$ sodium hydrogen carbonate solution $\left(2 \times 2 \mathrm{~cm}^{3}\right)$ and dried over MgSO4. The solvent was removed in vacuo and the crude product purified by flash chromatography (hexane:ethyl acetate, 4:1) to give the title compound 5 as a yellow solid $(160 \mathrm{mg}, 63 \%), \mathrm{mp} 127-130{ }^{\circ} \mathrm{C}$; [a] $20 \mathrm{D}=+88.0$ o $(\mathrm{c} \quad 0.12$, $\mathrm{CH}_{2} \mathrm{C}_{12}$ ). The $1 \mathrm{H}$ and $13 \mathrm{C}$ NMR data were in agreement with those reported previously. ${ }^{5}$ 
(6bR,9aR)-6-Acetyl-6b,9a-dihydro-5-hydroxy-7H-cyclopenta[b]naphtho[1,2- $d]$ furan (6). A solution of aldehyde $5(28 \mathrm{mg}, 0.11 \mathrm{mmol})$ in diethyl ether $(10 \mathrm{~cm} 3)$ at 0 o C was treated with a solution of methyllithium ( $222 \mu \mathrm{L}$ of $1 \mathrm{M}$ in THF, 2 equiv) and the reaction mixture stirred for 15 min. The reaction mixture was diluted with ether $(10 \mathrm{~cm} 3)$, washed with saturated ammonium chloride solution $(10 \mathrm{~cm} 3)$ and dried over MgSO4. The solvent was removed in vacuo to afford the crude alcohol as a pale yellow oil. The oil was dissolved in dichloromethane $\left(10 \mathrm{~cm}^{3}\right)$, activated manganese dioxide (40 mg) added and the reaction mixture stirred for $2 \mathrm{~h}$. The mixture was filtered through Celite and the solvent removed under reduced pressure. Purification of the residue by flash chromatography (hexane:ethyl acetate, 6:1) afforded the title compound 6 (21 $\mathrm{mg}, 72 \%$ ) as yellow needles, mp 162-163 oC. The $1 \mathrm{H}$ and 13C NMR data were in agreement with those reported previously4 for material of lower enantiomeric excess which had been prepared by an alternative method. The material prepared as described above exhibited $[\alpha]^{20} \mathrm{D}=$ +90.50 ( $c$ 0.4, $\mathrm{CH} 2 \mathrm{Cl} 2$ ) and the enantiomeric excess was determined to be $96 \%$ as measured by HPLC using a Pirkle Type 1-A column using hexane/ $0.5 \%$ isopropyl alcohol as solvent. The two enantiomers had retention times of $60.7 \mathrm{~min}$ and $64.2 \mathrm{~min}$.

$(3 \mathrm{a} R, 5 R, 11 \mathrm{bS})-3 \mathrm{a}, 5,11 \mathrm{~b}-$ Trihydro-5-hydroxy-5-methyl- $1 H$-cyclopenta[b]naphtha-

[2,3d]pyran-6,11-dione (7). Methyl ketone 6 (32 mg, $0.12 \mathrm{mmol}$ ) and silver(II) oxide (60 mg, 4 equiv) were mixed in dioxane $\left(3.0 \mathrm{~cm}^{3}\right)$ and nitric acid $\left(1.36 \mathrm{M}, 0.53 \mathrm{~cm}^{3}\right)$ was added. After stirring the resultant mixture for $5 \mathrm{~min}$ further portions of silver(II) oxide (60 mg, 4 equiv) and nitric acid $\left(1.36 \mathrm{M}, 0.53 \mathrm{~cm}^{3}\right)$ were added. Stirring was then continued for $10 \mathrm{~min}$ and water $(6$ $\mathrm{cm} 3)$ added. The aqueous layer was extracted with dichloromethane $\left(2 \times 5 \mathrm{~cm}^{3}\right)$, washed with water $\left(5 \mathrm{~cm}^{3}\right)$, dried $(\mathrm{MgSO} 4)$ and the solvent removed under reduced pressure. The residue was purified by flash chromatography (hexane:ethyl acetate, 4:1), affording the title compound 7 (32 mg, 95\%) as a pale yellow oil; IR (film) vmax/cm-1 3466, 1665, 1594, 1325, 1290; 1H NMR $(200 \mathrm{MHz}, \mathrm{CDCl} 3) \delta 1.82(3 \mathrm{H}, \mathrm{s}, \mathrm{Me}), 2.18-2.49(1 \mathrm{H}, \mathrm{m}, \mathrm{H}-1 \mathrm{~A}$ or H-1B), 2.93-3.21 (2H, m, H1B or H-1A and H-11b), 4.90-5.04 (1H, m, 3a-H), 5.92-6.07 (1H, m, H-2 or H-3), 6.23-6.34 (1H, m, H-3 or H-2), 7.70-7.83 (2H, m, H-8 and H-9), 8.01-8.15 (2H, m, H-7 and H-10); 13C NMR (50 MHz, CDCl3) $\delta 28.2$ (CH3, Me), 36.0 (CH, C-11b), 37.1 (CH2, C-1), 73.9 (CH, C-3a), 86.7 (C, C-5), 126.0 (CH, C-7 or C-10), 126.4 (CH, C-10 or C-7), 129.7 (CH, C-2 or C-3), 132.3 (C, C-6a or C-10a), 132.4 (C, C-10a or C-6a), 133.6 (CH, C-8 or C-9), 133.9 (CH, C-9 or C-8), 139.3 (CH, C-3 or C-2), 139.3 (C, C-11a), 144.5 (C, C-5a), 182.1 (C, C-6 or C-11), 184.0 (C, C11 or C-6); MS (CI, CH4) m/z 283 (M+ + 1, 10), 267 (30), 215 (15), 79 (100); HRMS (LSIMS) $m / z$ 283.0965 C17H14O4 requires $(\mathrm{M}++1) 283.0970) ;[\alpha]^{20} \mathrm{D}=+56.3$ o $(c 1.7, \mathrm{CH} 2 \mathrm{Cl} 2)$. 


\section{$(3 a R, 5 R, 11 b S)-3 a, 5,11 b-T r i h y d r o-5-m e t h y l-1 H$-cyclopenta[b]naphtho[2,3- $d]$ pyran-6,11-}

dione (8). Trifluoroacetic acid $(0.22 \mathrm{~cm} 3,2.8 \mathrm{mmol})$ and triethylsilane $(0.3 \mathrm{~cm} 3,2.8 \mathrm{mmol})$ were added dropwise to a solution of $7(126 \mathrm{mg}, 0.45 \mathrm{mmol})$ in dichloromethane $(15 \mathrm{~cm} 3)$ at -30 o C under an atmosphere of nitrogen. The reaction mixture was stirred for $15 \mathrm{~min}$ at -30 o $\mathrm{C}$ and then for a further $1.5 \mathrm{~h}$ at room temperature. The solvent was removed under reduced pressure and the residue purified by flash chromatography (hexane:ethyl acetate, 4:1) to afford the title compound 8 oil (61 mg, 51\%) as a yellow oil; IR (film) vmax/cm-1 1661, 1595, 1327, 1293; 1H NMR (200 MHz, CDCl3) $\delta 1.57$ (3H, d, J 6.6 Hz, Me), 2.24-2.51 (1H, m, H-1A or H-1B), 2.973.23 (2H, m, H-1B or H-1A and H-11b), 4.45-4.59 (1H, m, H-5), 4.70-4.85 (1H, m, H-3a), 5.92$6.07(1 \mathrm{H}, \mathrm{m}, \mathrm{H}-2$ or H-3), 6.16-6.27 (1H, m, H-3 or H-2), 7.66-7.78 (2H, m, H-8 and H-9), 7.98$8.13(2 \mathrm{H}, \mathrm{m}, \mathrm{H}-7$ and $\mathrm{H}-10)$; 13C NMR (50 MHz, CDCl3) $\delta 21.0(\mathrm{CH} 3, \mathrm{Me}), 36.1$ (CH, C-11b), 37.7 (CH2, C-1), 69.2 (CH, C-3a), 78.8 (CH, C-5), 126.1 (CH, C-7), 126.1 (CH, C-10), 130.5 (CH, C-2 or C-3), 131.9 (C, C-6a or C-10a), 132.4 (C, C-10a or C-6a), 133.5 (CH, C-8 or C-9), 133.7 (CH, C-9 or C-8), 138.0 (CH, C-3 or C-2), 144.2 (C, C-5a), 147.0 (C, C-11a), 184.2 (C, C6 or C-11), 184.4 (C, C-11 or C-6); MS (EI) m/z 266 (M+, 100), 251 (64), 224 (59), 165 (44), 103 (46); HRMS (EI) m/z 266.0929 (C17H14O3 requires 266.0943); [ $\alpha] 20 \mathrm{D}=+99.0$ o $(c \quad 0.4$, $\mathrm{CH} 2 \mathrm{Cl} 2)$.

\section{Acknowledgements}

We are grateful to the Australian Research Council (ARC) and The University of Sydney for financial support.

\section{References and Notes}

1. For a review see: Brimble, M. A.; Nairn, M. R.; Prabaharan, H. P. Tetrahedron 2000, 56, 1937.

2. For a leading reference see: Giles, R.G. F.; Joll, C. A.; Sargent, M. A.; Tilbrook, D. M. G. J. Chem. Soc., Perkin Trans. I 1999, 3029.

3. For a recent example see: Brimble, M. A.; Nairn, M. R.; Park, J. J. Chem. Soc., Perkin Trans. 1 2000, 697.

4. Brimble, M. A.; McEwan, J. F. Tetrahedron Asymmetry 1997, 8, 4069.

5. Brimble, M. A.; McEwan, J. F. Turner, P. Tetrahedron Asymmetry 1998, 9, 1239.

6. Brimble, M. A.; McEwan, J. F. Turner, P. Tetrahedron Asymmetry 1998, 9, 1257. 
7. Kraus, G. A.; Molina, M. T.; Walling, J. A. J. Org. Chem. 1987, 52, 1273. 